INTERNATIONAL HIGHER EDUCATION Number 75 Spring 2014

Pages 12-13

\title{
China's Removal of English from Gaokao
}

YANG RUI

Yang Rui is professor and director, at the Comparative Education Research Center, University of Hong Kong, Pokfulam Road, Hong Kong, China. E-mail: yangrui@hku.hk.

Embracing the English language exemplifies China's vigorous engagement with the outside world, especially in respect to Western societies. The attitude is not only unprecedented in Chinese modern history, but is also different from other developing countries' interactions with the developed Western world. At both national, and individual, career development levels, English-language education has been a subject of paramount importance in China since its reopening to the outside world. Proficiency in English has been widely regarded as a national, as well as a personal asset. English-language education has been viewed by the Chinese, both the leadership and the people, as having a vital role to play in national modernization and development.

Seeing the dominant status of English as a historical fact, China has initiated various policies to adapt to it, instead of resisting it, in an effort to promote internationalization. Learning English is no longer just important within China. It is the bare minimum for any serious student. China is home to more speakers of English than any other country. Examinations in Chinese schools at 
all levels include English proficiency tests. English is widely required in the professional promotions of academics, including many whose work requires little use of English. With the proposed changes in the gaokao (China's national college entrance examination), the extraordinary phenomenon of a huge option in China of learning English is likely to fade.

\section{The Reform Plan}

As part of China's reform plan to change its notorious once-in-a-lifetime examination system, the Ministry of Education foreshadowed in late 2013 that the English test will be removed from the gaokao by 2020. Instead, tests will be held several times a year for students to choose when and how often they achieve the examination so as to alleviate study pressure, and only the highest score they obtain will be counted. It will be piloted in selected provinces and cities and promoted nationwide from 2017, with a new examination and an admission system projected to be established by 2020 .

Even before the Ministry of Education's release, the Beijing Municipal Commission of Education had said that the scores for subjects in Beijing's gaokao will change as of 2016. The overall score of English language will drop from 150 to 100 , while the total points for Chinese language will rise from 150 to 180 . Mathematics remains unchanged at 150 points. Arts and sciences overall increased from 300 to 320 points. The English-language test can be taken twice a year. If a student gets 100 points in the first year of high school, for example, then she or he can be exempted from English courses in the second and third years.

Other regions, including Jiangsu and Shandong provinces and Shanghai municipality, are also preparing their own gaokao reforms. Shandong was 
reported to cancel the listening part of the English-language examination in its gaokao. In Jiangsu, there have been discussions of excluding English in gaokao in the future. While details remain to be finalized, the general direction is clear: less English, more Chinese for gaokao.

\section{The Debate}

The reform initiative has won overwhelming support from the general public. In a survey of over 220,000 respondents updated in December 9 last year by Phoenix Online, when asked about their views on Beijing's gaokao reform, 82.82 percent supported it while only 13.55 percent were opposed. Similarly, when asked if they would support lowering the point value for English language and increasing the point value for Chinese language, 82.79 percent supported and 13.01 percent opposed.

In contrast, the plan has divided education experts, who disagree on whether placing less emphasis on English-language skills is a good idea. The decision has aroused heated discussions among those who doubt the reform would reduce the burden of learning English or if the substitute test could reflect a student's English skills and help students learn English better. An important aspect of the reform lies in what and how to test, as suggested by Yu Lizhong, chancellor of New York University Shanghai. The education ministry adds to the complex of the debate by viewing removing English from gaokao as an indicator of China's cultural confidence.

Most debates focus on whether or not the reform could relieve the burden of gaokao and how to distribute time to study the native language and a foreign one (English). Hu Ruiwen, who is based at Shanghai Institute for Human 
Resources Development and a member of the National Education Advisory Committee, said such a change would be a signal to students that they should pay more attention to their mother tongue than a foreign language. To him, students now spend too much time studying English. There is a need for them to learn their native language well. He believes the changes will help students better to learn the Chinese language.

Cai Jigang, a professor at Fudan University's College of Foreign Languages and Literature and chairman of the Shanghai Advisory Committee for College English Teaching at Tertiary Level, opposes any plan to reduce the status of English language in the college entrance exam because it fails to take into account China's demand for foreign-language ability—as a means to accept the challenge of globalization and the internationalization of higher education. He worries that Chinese students may no longer work hard on English, which will have an adverse effect in the long run.

\section{Missing The Point?}

The central emphasis on the strategic role of English in the modernization process and the high priority given to that language on the national agenda of educational development has proven to be beneficial. China's efforts are already paying off. The communicative and instrumental function of English as a global language has accelerated China's foreign trade and helped China's economic growth in the past decades. It has also promoted China's exchanges with the outside world. Chinese scholars and students in major universities have little difficulty in communicating with international scholars. Their English proficiency has contributed to China's current fast, successful engagement with 
the international community. Peer-reviewed papers in international journals written by Chinese researchers rose 64 -fold over the past 30 years.

China's modernization began with foreign-languages learning. In consequence, it could be argued that attitude toward foreign language has been the harbinger of China's internationalization. Instead of demonstrating confidence, the decision reveals a degree of cultural indulgence. The gaokao is likely to remain the most important indicator for college admissions: deemphasizing English, rather than taking the chance to make it less test-based, with a greater emphasis on practical proficiency, will reduce schools' and students' efforts to learn English, at a time of rising demand for proficient English-speaking Chinese employees. If this was the result, would it limit the chance for China to continue its recent success story? 